\title{
Erratum to: Emergency Radiology: Imaging of Acute Pathologies
}

\author{
Ajay Singh
}

\section{Erratum to:}

\section{A. Singh (ed.), Emergency Radiology, https://doi.org/10.1007/978-3-319-65397-6}

The original version of the book had incorrect affiliations for the below chapter authors and these changes have been updated in the chapters $1,10,17,20,24,25$, and 26 and as well as in the front matter.

\footnotetext{
The updated online version of these chapters can be found at https://doi.org/10.1007/978-3-319-65397-6_1 https://doi.org/10.1007/978-3-319-65397-6_10 https://doi.org/10.1007/978-3-319-65397-6_17 https://doi.org/10.1007/978-3-319-65397-6_20 https://doi.org/10.1007/978-3-319-65397-6_24 https://doi.org/10.1007/978-3-319-65397-6_25 https://doi.org/10.1007/978-3-319-65397-6_26
}

The updated online version of this book can be found at https://doi.org/10.1007/978-3-319-65397-6 